\title{
Construing Masculinity in Men's Perfume Advertisement: A Systemic Functional Multimodal Discourse Analysis (SF-MDA)
}

\author{
Laily Maulida Septiana Harti \\ Universitas Negeri Surabaya \\ Surabaya, Indonesia \\ lailyharti@unesa.ac.id
}

\begin{abstract}
This qualitative research examines the construction of masculinity in men's perfume advertisements through the employment of visual images and verbal elements. Fifteen advertisements from Cosmopolitan, ELLE, Men's Health and Men's Fitness magazines 2015-2016 edition were collected online and analysed using O'Halloran's (2008) Systemic Functional Multimodal Discourse Analysis (SF-MDA) framework. The results demonstrate that both verbal and visual modalities are used effectively as a medium for representing the proposed masculinity, in which masculinity is portrayed as men being intense, serious, stylish, adventurous, sporty while at the same time elegance and pure, as the concept of newmannist proposed by Gregorio-Godeo (2009) has taken the lead. In addition, being masculine is nowadays separated from men's role in relation to women or family life.
\end{abstract} MDA

Keywords - masculinity, men's perfume advertisement, SF-

\section{INTRODUCTION}

Fashion magazine has been one of the important media in advertising industry, especially as a channel to disseminate a particular belief, in which its readers are submitted to when it comes to constructing their identities [1]. Discussed in this paper is the construction of discourse of masculinity in the selected fashion magazines particularly from men's perfume advertisements published in the magazines. It is observed that the visual images and verbal language are employed together to portray the masculine lifestyle. These multimodal semiotic resources are brought together by the advertisers to influence their potential buyers' decision about purchasing the advertised items.

The study of masculinity lies under the study of gender. The study of gender in advertisement is firstly introduced by Goffman [2] through the representation of the male and female models, their social roles, and their position towards the concept of family. For many years, in general, men are portrayed to be on higher power position showing the patriarchal stereotype, to take lead in the relationship with their female counterparts, and to be portrayed with family touch [2]. This is how the traditional masculinity is depicted. The concept of masculinity is slowly growing and is depicted differently from once it is used to be. Several previous research claimed that men are then associated with alcohol [3] - [5], sport car [6], and other sport activities [7]
- [8], which posits them to be macho, strong, adventurous and are related to dangerous activities.

The portrayal of masculinity is also grounded and popularized in fashion industry. Being a commodity, masculinity is treated as a trading goods, in which its possession can be obtained through buying the carrier of masculinity-value products. In fashion industry, moreover, masculinity has been closely related to consumption, and excessively to addiction of lifestyle [9]. Gregorio-Godeo [9] proposed that the employment of male participants, supported with other semiotic resources such as linguistic elements, angle, colour, and composition, are promoting the newmannist perspective of masculinity. Thus, this study is aimed to provide further corpus-based investigation on the concept of masculinity proposed in the original study by addressing two questions:

1) What visual and linguistic elements are employed in the selected male-fragrance's advertisements?

2) How does the interplay between linguistic and visual elements create a coherent meaning-making system in the discursive representation of masculinity in the selected male-fragrance's advertisements?

\section{Methods}

The advertisements analysed in this study were selected online (from https://archive.org) comprised from Cosmopolitan, ELLE, Men's Health and Men's Fitness magazines, published and distributed throughout the USA, England and Australia from 2015 to 2016. This study employed longitudinal data collection, aiming to describe the trend of the perceived masculinity in the advertising campaigns where male models are employed in most of the advertisements.

The descriptive analysis will be given under two points of evaluation, including 1) the employment of visual and linguistic elements, and 2) the interplay between the elements in decoding the discourse of masculinity in the perfume advertisements. In doing so, Systemic Functional Multimodal Discourse Analysis (SF-MDA) framework [10] is utilized to analysed the linguistic elements of the advertisements, with reference to the theory of grammar of visual design [11] - [12] to analyse the representations, engagements and compositions between the linguistic and visual elements of the advertisements. 


\section{RESULTS AND DISCUSSION}

The results and discussion will be presented to directly answer the two main questions of this study in two sections. Under the first section, this corpus-based study presents the discussion on purpose, medium and design underpinning the result in construing the concept of masculinity.

\section{A. Visual and Linguistics Elements in the Advertisements}

Following Cheong's classification of linguistic and visual elements [13], the generic structure potential of print advertisement is composed by Lead, Display, Emblem, Announcement, Enhancer, Tag and Call-and-Visit Information. However, Enhancer element is absent in all advertisements. Cheong [13, p. 173] describes Enhancer as linguistic element that "details the advertisers' reasoning/ argument as to why the product is worth the customers' attention and money [in other words, its function is] to persuade and influence viewers to purchase the product”. This element is usually written in a long paragraph. The absence of Enhancer in the men's perfume advertisements shows that the advertisers prefer to make the campaigns short and precise, by avoiding putting more information about the product. This also indicates that the discourse of masculinity is portrayed as being simple and uncomplicated.

The linguistic and visual elements simultaneously employed in the advertisements to complement each other according to their own affordances, to create meanings that might be unable to be represented by one mode only [12]. In addition, as the purpose of these advertisements is to promote the products to the targeted audiences, while at the same time to infiltrate remarkable masculinity concept, these elements are designed and enhanced with colour and positioning. Detail explanation on the design and the interplay between linguistic and visual elements is presented in the next section.

\section{B. The Interplay between Elements in the Advertisements}

This section discusses the interplay between linguistic and visual elements in the advertisements. The interplay between the linguistic and visual elements are discussed in terms of their representations, engagements, and compositions employed in the advertisements.

\section{1) Representations}

Representation encompasses the ideational metafunction of the multimodal text. It is related to the participant, process and circumstances that play role in the advertisements. It is observed that the participants of the perfume advertisements are the advertised products (in all selected advertisements) and the male models (all advertisements except ad 6). The male models are depicted in attractive pose, some of them are fashionably dressed up (advertisements 1, 2, 3, 7, 8, 12, 13, 15) or pictured in sportswear (advertisements 11, 14), slightly showing their chest (advertisement 5), and even some are topless (advertisements 4, 9, 10). Most of the models are represented alone, far from its original portrayal of men which was related to their role in family.

The advertisers employ symbolic processes in representing the visual element. Symbolic process tells "what a participant means or is" [11, p. 108]. To be precise, the male models act as the Symbolic Attribute in which they represent the identities suggested by the perfume itself, while the advertised products act as Carrier of the proposed manliness value. In other words, the male models have the projected value of what being men means, as the result of using the perfume.

It is observed that the advertisements use ellipsis on the verb Process (in bold).

\begin{tabular}{|l|c|l|}
\hline $\begin{array}{l}\text { Mercedes-Benz } \\
\text { Man }\end{array}$ & (is) & the star fragrance \\
\hline [Carrier] & $\begin{array}{c}\text { ([relational } \\
\text { attributive } \\
\text { Process]) }\end{array}$ & [Attribute] \\
\hline \multicolumn{3}{|c|}{ (advertisement 2) } \\
\hline Cédrat & (is) & a force of freshness \\
\hline [Carrier] & $\begin{array}{c}\text { ([relational } \\
\text { attributive } \\
\text { Process] }\end{array}$ & [Attribute] \\
\hline & (advertisement 6) \\
\hline
\end{tabular}

In addition, material Processes are found in the advertisements, in which the value that the male models represent are the goals obtained as the effect of using the perfume.

\begin{tabular}{|l|c|l|}
\hline It all & starts & with a dream \\
\hline [Goal] & [material Process] & [Actor] \\
\hline \multicolumn{3}{|c|}{ (advertisement 9) } \\
\hline
\end{tabular}

\begin{tabular}{|l|l|l|l|}
\hline Success & isn’t born & It (success) & 's made \\
\hline [Goal] & $\begin{array}{c}\text { [material } \\
\text { Process] }\end{array}$ & [Goal] & $\begin{array}{l}\text { [material } \\
\text { Process }\end{array}$ \\
\hline \multicolumn{3}{|c|}{ (advertisement 15) } \\
\hline
\end{tabular}

Thus, it can be said that not only the visual imagery represents the value of represented manliness, the linguistic representation also indicates that these fragrances have essential role in constructing masculinity value. In addition to the processes mentioned earlier, the use of adjective new in half of the advertisements (advertisements 1, 3, 4, 6, 8, 9, 13, 14) enacts that men are becoming the active consumers of this grooming product, thus there is a need to introduce the new version of the product. This shows that men also care about their personal appearance. This issue has been of great research interest as male-grooming concept is on the rise.

\section{2) Engagements}

To engage the potential buyers, the advertisers make use of some variables such as modality, gaze and the social distance through the angle of shot. Regarding to the modality, the advertisers employ various colour differentiation and saturation. The use of blue-black hue shows the peaceful, serious, male principle while at the same time being sharp [14, p. 354]. In advertisement 6 , the designer uses green to campaign the purity side of the manliness. These backgrounds are used in contrast to the advertised perfume bottle to attract the readers' attention.

Most of the models are shot in medium proximity, creating space or social distance between them and the readers. Depicted in staring position, this shows the connectedness between the readers and the models. This result shows that it is the advertisers' attempt to engage the readers in intimate nuance [9]. As the Attribute, the models are depicted in doing active activities such as sailing, acting, racing, footballing and even gambling. These activities indicate the adventurous characteristics of men. 
As for the linguistic element, the advertisers specify the targeted market of the products, which is indicated by explicitly mentioning the new fragrance for men (advertisement 3, 4, 5, 6,11 ) and even making the attribution as the product's name, as seen in advertisement $1 \mathbf{L}$ 'HOMME PRADA. The lack use of modality markers in the advertisements enact the presumption that there is a writer-reader personal and eye to eye communication. This makes engagement with the readers stronger as the readers will feel as if the products and the models are directly sharing the value of masculinity with them. From marketing viewpoint, this will increase the readers' affirmative decision to buy the product.

\section{3) Compositions}

Compositions relate to the information value, salience and positioning or layout of the advertisements. Information value is depicted through the positioning of the information inside the text, especially those located in the centre position. It is most likely that the male models, as the symbolic attributive that carry the value of manliness from the perfume they use, are positioned in the centre. It indicates that central position is the most attention-attractor [11], [15]. In addition, as discussed earlier under the engagements sub-section, the advertisements make use of contrast colour between the advertised perfumes and the background. This employment makes the models and the products salient in the advertisement. It makes the readers commit themselves to those two entities in the advertisement, indicating that the advertisers deliberately compose their advertisements in a way that the value of manliness is addressed directly to the readers.

In advertisements $6,10,11,12,13$, the perfume products are placed in central position. Shown in advertisement 10, 11, 12 and 13, these two-page advertisements posit their products and the male models in the same central position, showing the equality of value between the product and the model. While in advertisement 15 , what posits in the central position is the model and the linguistic element "SUCCESS ISN'T BORN. IT'S $M A D E$ ” with the product located beneath the words. It indicates that the product itself will help the users to become success just like the model.

\section{CONCLUSION}

As presented in the result and discussion section above, the linguistic and visual elements employed in the selected advertisements are Lead, Display, Emblem, Announcement, Tag, and Call-and-Visit Information. With the absence of Enhancer, this indicates that being simplistic is considered to best describe masculine value. In addition, the interplay between those elements are evidenced in the representation, engagement and composition of the advertisements, in which all aspects are working together to create a deeper impression towards the targeted audience of the potential buyers. Overall, the elements in the selected men's perfume advertisements support the newmannist value of masculinity, in which men are portrayed to be intense, serious, stylish, adventurous, sporty while at the same time elegance and pure. This value of masculinity has changed from the traditional viewpoint in which men are portrayed as the lead of family only.

As this study only employed limited number of data, thus to make a description on the trend of masculinity to date, especially to the change in trends and perceptions of masculinity, it is suggested that further research is to be conducted in the area of current advertising campaigns and even to other genre of discourse in which male models are employed in its text production.

\section{REFERENCES}

[1] A. Goddard, The language of advertising: Written texts. London: Routledge, 1998.

[2] E. Goffman, Gender advertisements. USA: Harper \& Row, 1979.

[3] T. Smith, "Pumping irony: The construction of masculinity in a postfeminist advertising campaign," Advertising \& Society Review, vol. 6, no. 3, n. pag, Sep 2005.

[4] L. T. Zayer, "A typology of men's conceptualizations of ideal masculinity in advertising," Advertising \& Society Review, vol. 11, no. 1, n. pag, Apr 2010. Available: http://works.bepress.com/linda tuncay zayer/4/

[5] A. J. Towns, C. Parker, and P. Chase, "Construction of masculinity in alcohol advertising: Implication for the prevention of domestic violence," Addiction Research \& Theory, vol. 20, no. 5, pp. 389-401, Jan 2012.

[6] C. Duerringer, "Be a man, buy a car: Articulating masculinity with consumerism in man's last stand," Southern Communication Journal, vol. 80, no. 2, pp. 137-152, Apr 2015.

[7] P. Verdonk, H. Seesing, and A. de Rijk, "Doing masculinity, not doing health: A qualitative study among Dutch male employees about health beliefs and workplace physical activity,” BMC Public Health, vol. 10, no. 712, Nov 2010. [Online serial]. Available: https://www.ncbi.nlm.nih.gov/pmc/articles/PMC2998494/

[8] W. H. Cortenay, "College men's health: An overview and a call to action," Journal of American College Health, vol. 46, no. 6, pp. 279-290, May 1998.

[9] E. D. Gregorio-Godeo, “British men's magazines' scent advertising and the multimodal discursive construction of masculinity: A preliminary study," Estudios Ingleses de la Universidad Complutense, vol. 17, pp. 936, Oct 2009.

[10] K. L. O’Halloran, “Systemic functional-multimodal discourse analysis (SF-MDA): Constructing ideational meaning using language and visual imagery," Visual Communication, vol. 7, pp. 443-475, Nov 2008.

[11] G. Kress, and T. van Leeuwen, Reading images: The grammar of visual design. London: Routledge, 1996.

[12] G. Kress, "Multimodality: Challenges to thinking about language,” TESOL Quarterly, vol. 34, no. 2, pp. 337-340, Sum 2000.

[13] Y. Cheong, "The construal of ideational meaning in print advertisements," in Multimodal discourse analysis: Systemic functional perspectives, K. L. O’Halloran, Ed. London: Continuum, 2004, pp. 163195.

[14] G. Kress, and T. van Leeuwen, "Colour as a semiotic mode: Notes for a grammar of colour,” Visual Communication, vol. 1, no. 3, pp. 343-368, Oct 2002.

[15] G. Kress and T. van Leeuwen, Reading images: The grammar of visual design, 2nd ed. London: Routledge, 2006. 


\section{APPENDIX}

1. L’ Homme (by Prada): ELLE magazine UK, October 2016.

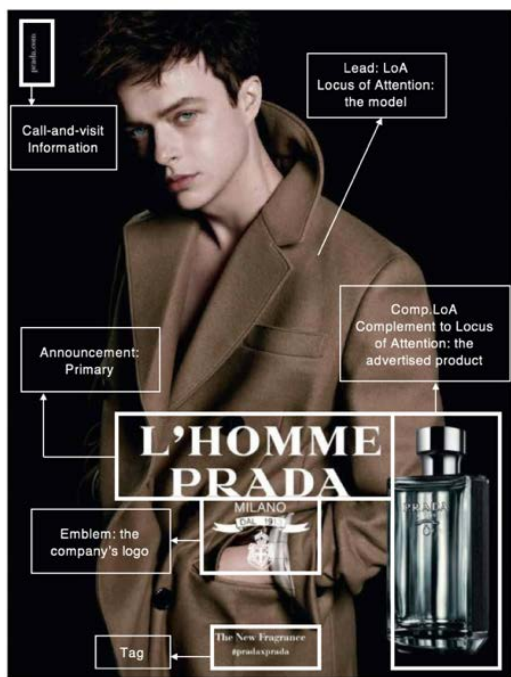

2. Mercedes-Benz Man (by MercedesBenz): Men's Health magazine AU, October 2016.

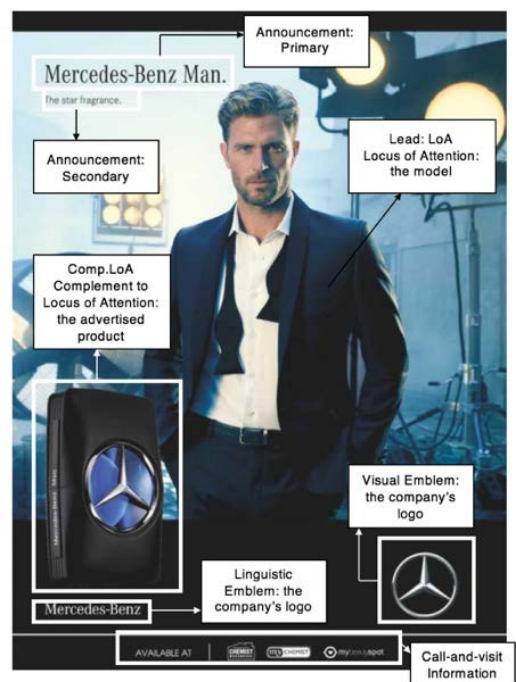

3. The Brilliant Game (by Davidoff): Men's Health magazine AU,

September 2015.

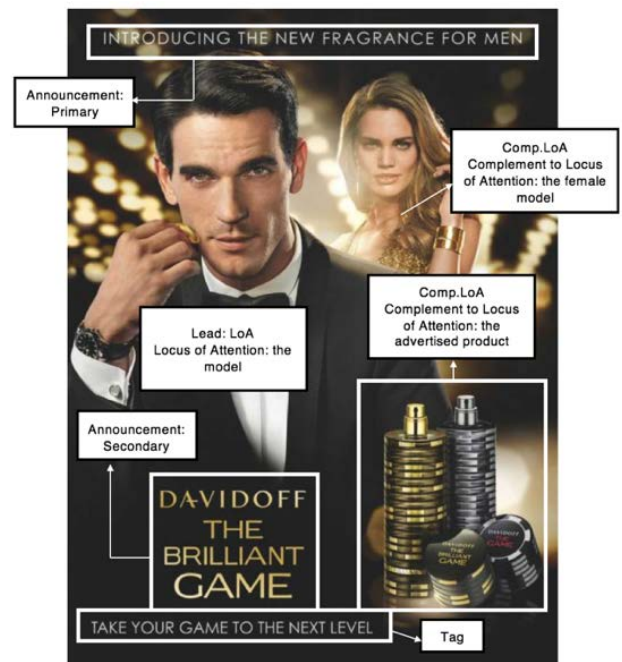

4. TH Bold (by Tommy Hilfiger): Men's Fitness magazine USA, December 2015.

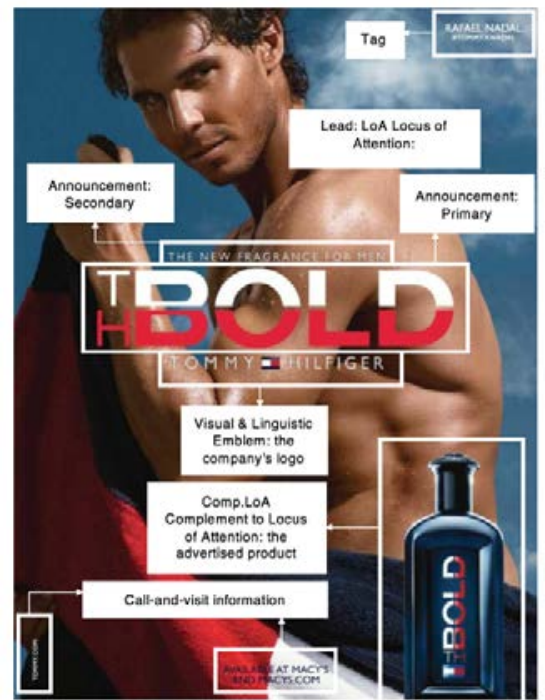

5. Voyage (by Nautica): Men's Fitness magazine USA, April 2016.

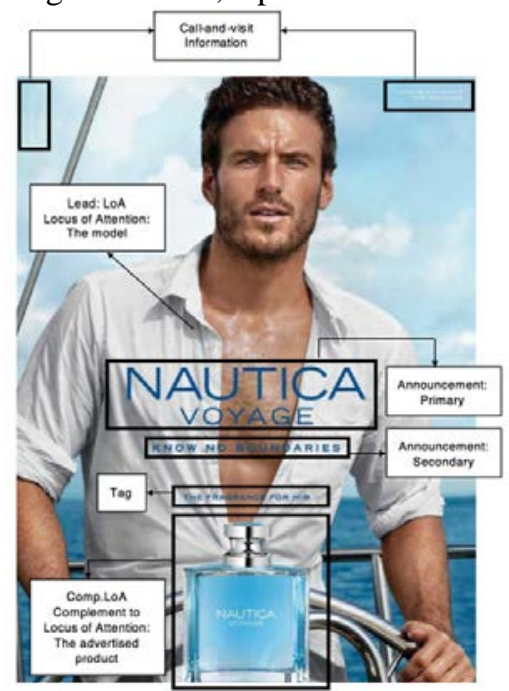

6. Cédrat (L'occitane): Men's Health magazine UK, February 2016.

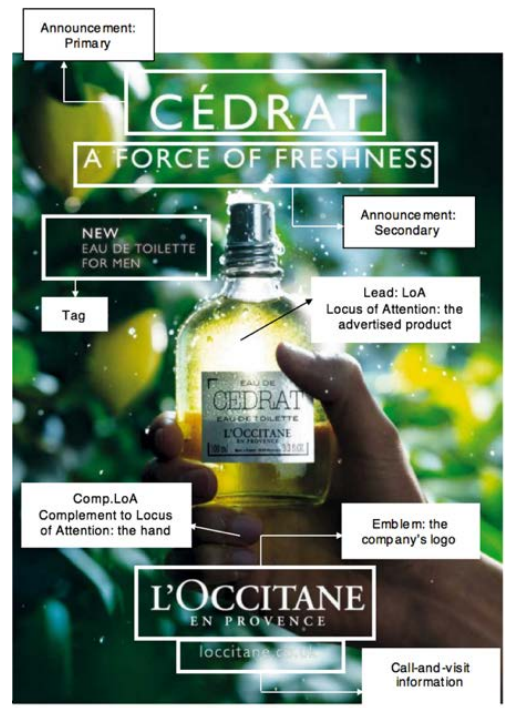

7. Instinct (by David Beckham): Men's Health magazine AU, March 2015.

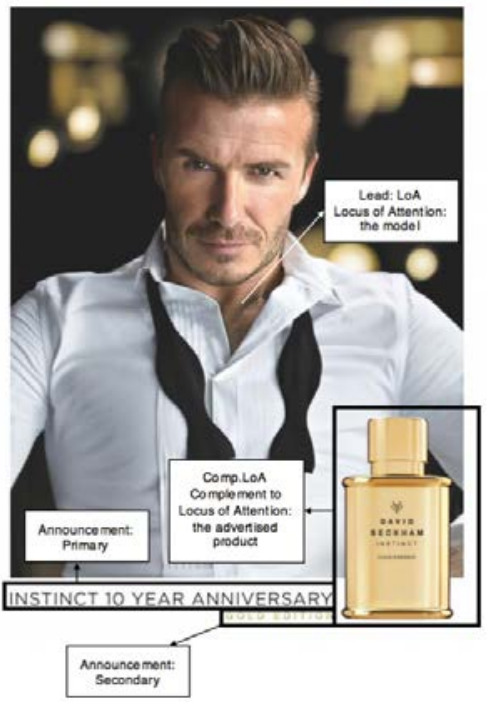

8. Intenso (by Dolce \& Gabbana): Men's Health magazine AU, March 2015.

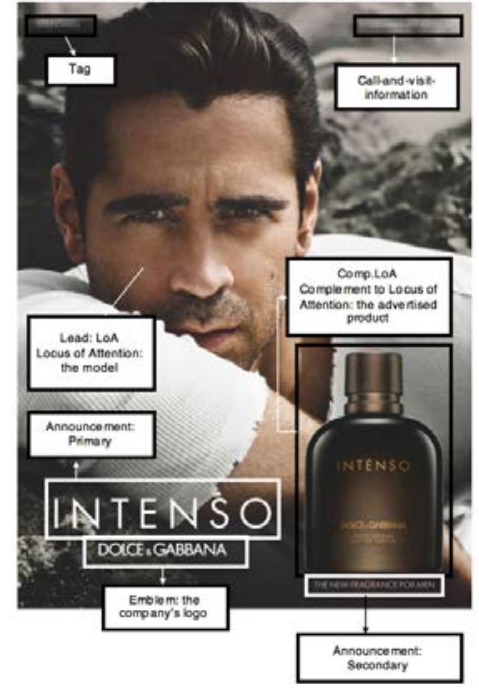

9. Beyond (by David Beckham): Men's Health magazine AU, September 2015.

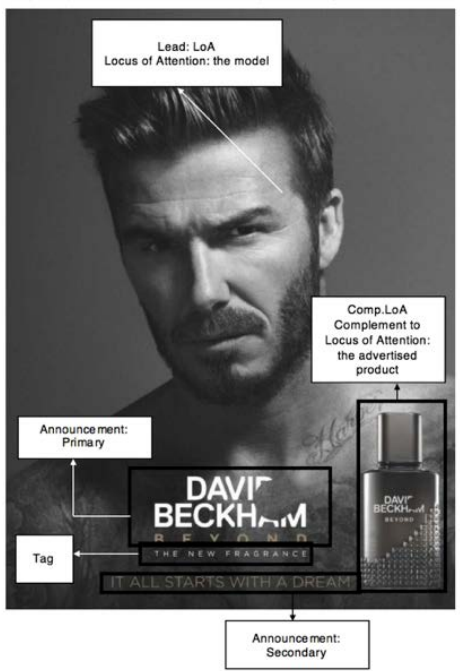


10. Acqua di Gio (by Giorgio Armani): Cosmopolitan magazine USA, June 2016 (left page).

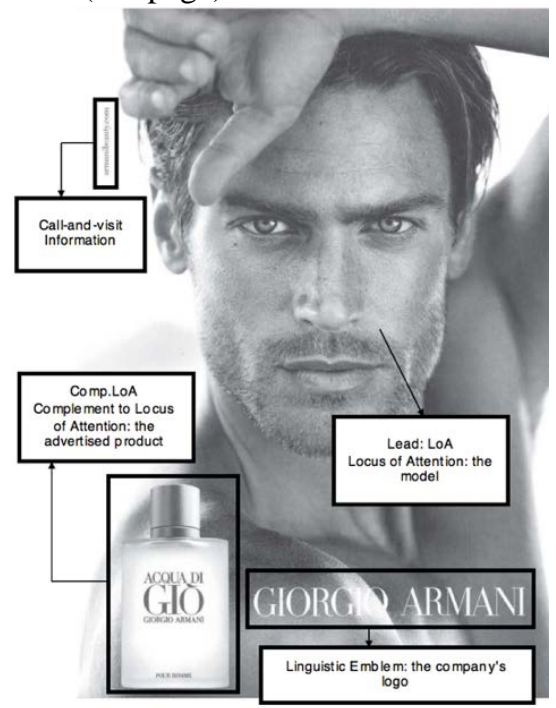

Acqua di Gio (by Giorgio Armani): Cosmopolitan magazine USA, June 2016 (right page).

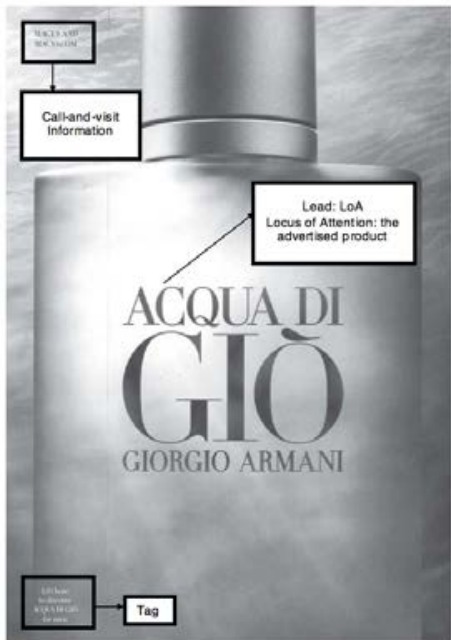

11.Polo Red (by Ralph Lauren): Cosmopolitan magazine USA, September 2016 (left page).

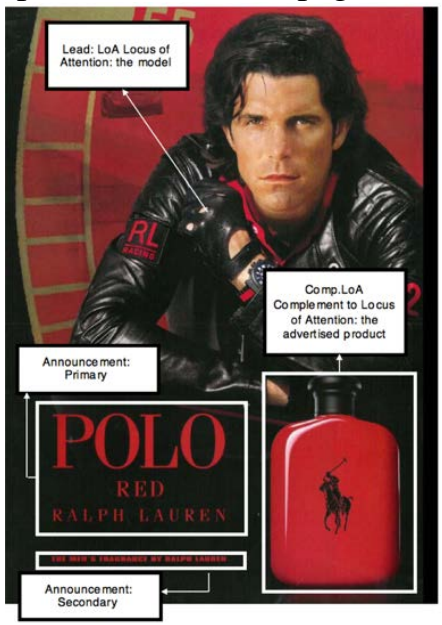

Polo Red (by Ralph Lauren): Cosmopolitan magazine USA, September 2016 (right page).

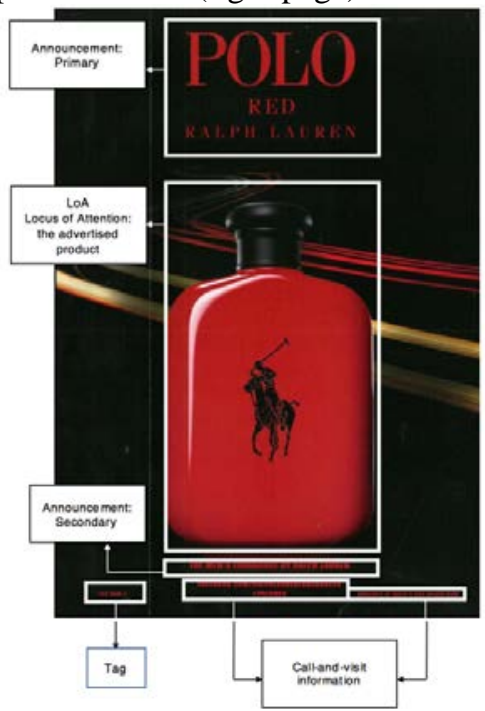

12. Man of the Day (by Boss Hugo Boss): Men's Fitness magazine USA, April 2016 (left page).

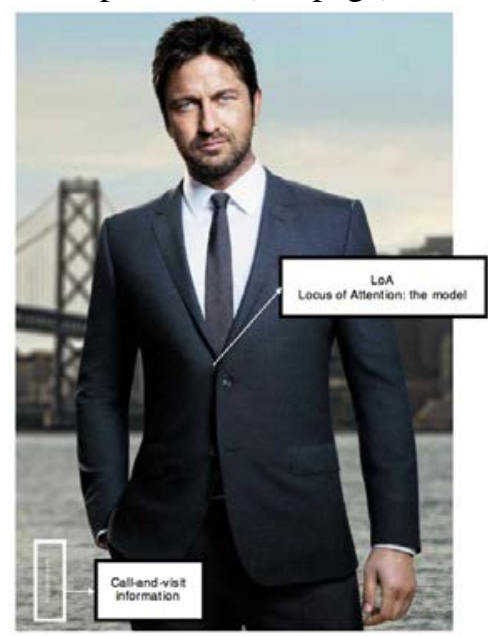

Man of the Day (by Boss Hugo Boss): Men's Fitness magazine USA, April 2016 (right page)

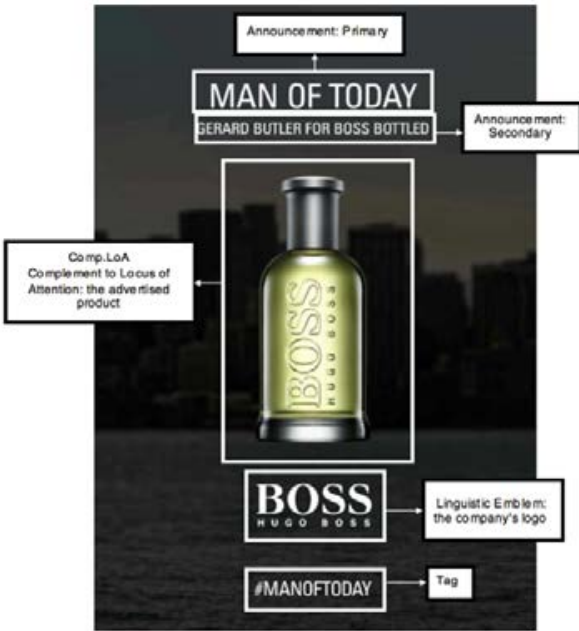

13.Sauvage (by Dior): ELLE magazine UK, June 2016 (left page).

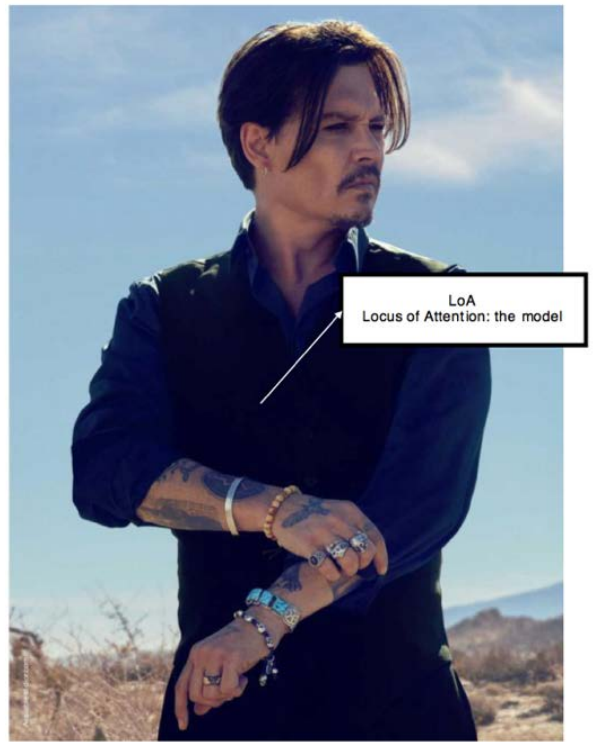

Sauvage (by Dior): ELLE magazine UK, June 2016 (right page).

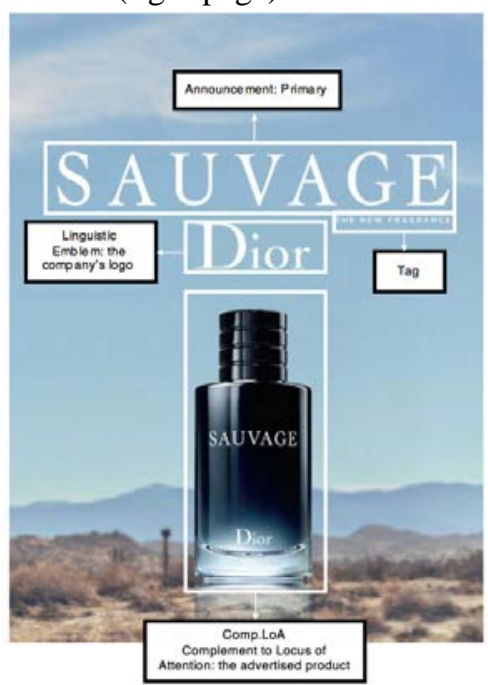

14.Luna Rosa Sport (by Prada): Men's Health magazine UK, June 2016 (left page).

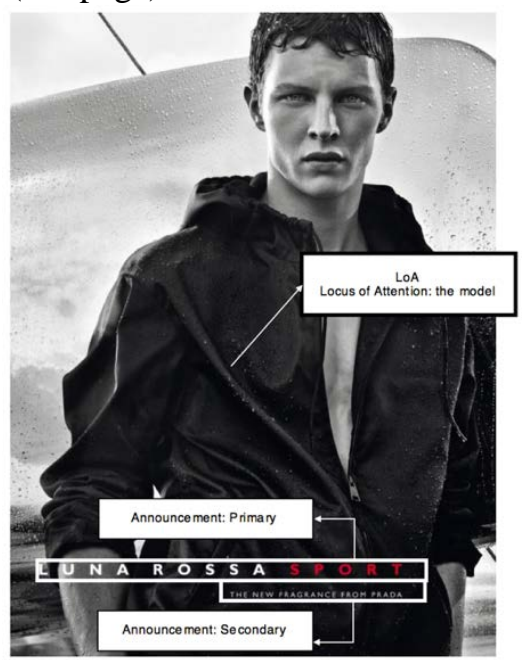


Luna Rosa Sport (by Prada): Men's Health magazine UK, June 2016 (right page).

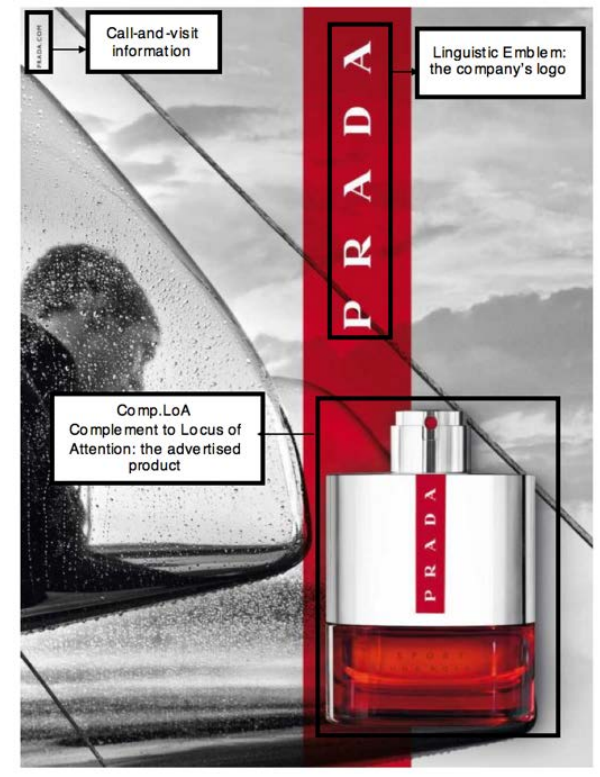

15. Boss (by Hugo Boss):

Men's Health magazine AU, June 2016 (left page).

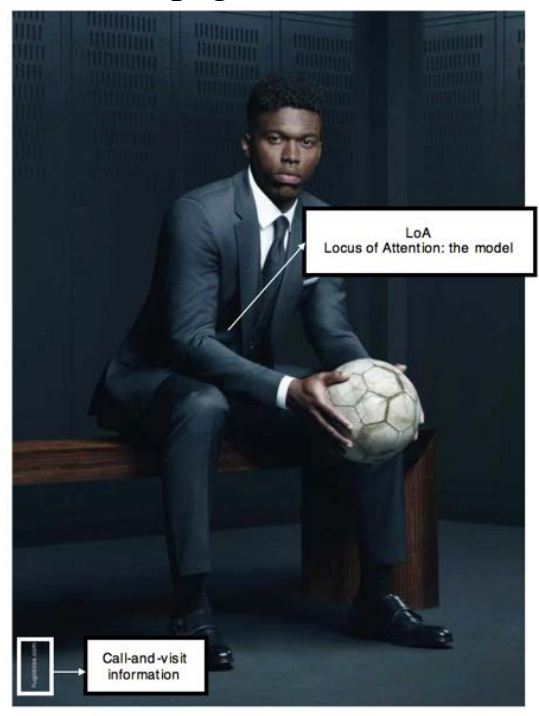

Boss (by Hugo Boss): Men's Health magazine AU, June 2016 (right page).

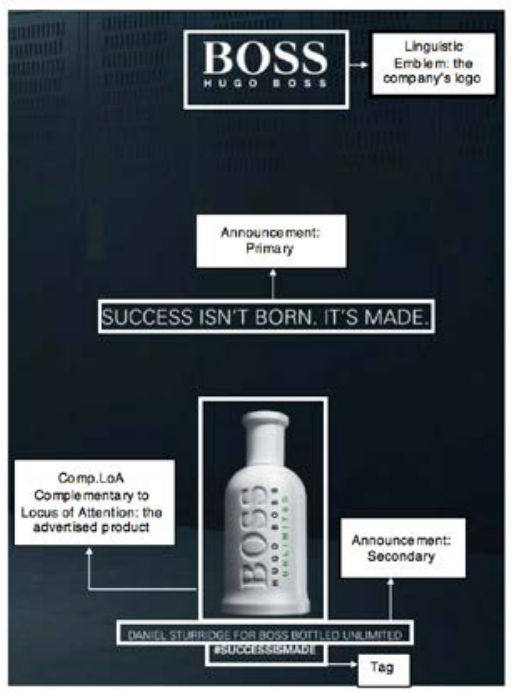

